\title{
Notas sobre la prohibición del testamento conjunto: sobre la validez de los mirror wills
}

\section{Alberto Maria BenedetTi ${ }^{* \star}$}

Resumen: El autor reconstruye las vicisitudes históricas del testamento conjunto (art. $5^{8} 9$ del codice civile), recorriendo las etapas de toda su evolución, y en consideración a que la prohibición del mismo tenía su justificación en la protección de la libertad testamentaria ante las posibles influencias indebidas. Se deduce que los llamados mirror wills o testamentos simultáneos de los cónyuges puede que no incurran en la prohibición del testamento colectivo, en la medida en que las voluntades de los testadores -en tanto identificadas y expresadas contemporáneamente- son tomadas en documentos diferentes.

Palabras clave: sucesiones, testamento conjunto, autonomía testamentaria, mirror will.

Trad. del italiano, Carlos Alberto Chinchilla Imbett.

Fecha de recepción: 27 de marzo de 2015 . Fecha de aceptación: io de agosto de 2015.

Para citar el artículo: A. M. BENEDETTI, "Notas sobre la prohibición del testamento conjunto: sobre la validez de los mirror wills", Revista de Derecho Privado, Universidad Externado de Colombia, n. ${ }^{\circ}$ 29, julio-diciembre de 201 5, pp. 59-72. DOI: http://dx.doi.org/ro. I860 I/or 234366.n29.03

** Doctor en Derecho. Profesor asociado de Derecho Privado de la Università degli Studi di Genova, Italia. Contacto: alberto.benedetti@unige.it 


\section{Notes on the probibition of joint wills: The validity of mirror wills}

Aвstract: This contribution traces the history of the prohibition of joint wills (Art. 589 of the Italian Civil Code), recalling the stages of its complex evolution. The protection of testamentary freedoms has historically served as the justification behind this prohibition, but today's case law reshapes the rule. Today, mirror wills between spouses shall be effective as long as each spouse's will is expressed as a separate document.

KEY wORDs: Wills, mirror wills, testamentary autonomy.

Sumario: i. La relatividad histórica y territorial de la prohibición del testamento conjunto. II. Viejas problemáticas que recobran actualidad: ¿prohibición de naturaleza formal o sustancial? III. Nuevas lecturas jurisprudenciales: ¿hacia la validez de los mirror wills? Bibliografía.

\section{La relatividad histórica y territorial de la prohibición del testamento conjunto}

El testamento es un acto unilateral. Afirmación incontrovertible que aparece, hoy y desde siempre, en todos los tratados sobre el testamento, en los apartes dedicados a la ilustración de sus características fundamentales ${ }^{\mathrm{I}}$. Su indiscutible unilateralidad constituye tal vez al mismo tiempo un límite, pues, como escribe Giorgio De $\mathrm{Nova}^{2}$, a veces el conjunto de disposiciones sucesorias pasa (o debería pasar) a través de decisiones bilaterales o plurilaterales que el testamento no es capaz de expresar (pero que, debido a la prohibición de los pactos sucesorios, tampoco puede efectuar el contrato en nuestro ordenamiento jurídico). De todos modos, la atribución del testamento a una sola persona se expresa directamente en la prohibición establecida en el artículo 589 del codice civile, cuya obligatoriedad es la misma de todas las normas imperativas: "non si può fare testamento a due o più persone nel medesimo atto, né a vantaggio di un terzo, né con disposizione reciproca".

I La unipersonalidad es un "carácter" de la personalidad: G. Bonilini, "Il negozio testamentario", en Trattato di diritto delle successioni e delle donazioni, dir. G. Bonilini, II, La successione testamentaria, Milán, 2009, p. 37; A. Palazzo, Le successioni, ${ }^{* *}$, en Tratt. dir. priv., Milán, 200o, p. 636. Sobre el particular véase también S. Pagliantini, Causa e motivi del regolamento testamentario, Nápoles, 2000, p. 74 (quien combina unilateralidad y espontaneidad, "dos atributos ya inmanentes a los artículos $45^{8}$ y $5^{89}$ c.c.").

2 G. De Nova, Il contratto. Dal contratto atipico al contratto alieno, Padua, 20 i I, p. Io9 (que sobre este punto toma, para aprobarlo, una idea de Palazzo). 
Generalmente esta prohibición (asistida de una nulidad que realmente no está regulada de manera expresa, sino que es textualmente implícita ${ }^{3}$ ) se considera como una confirmación de la unilateralidad del testamento, ya contenida en la formulación del artículo 587 , en cuanto contiene la misma definición ("taluno dispone..."4).

La patología que prefigura el artículo 589 del codice civile consiste en que en un mismo acto (en sentido rigurosamente formal) se encuentren contenidas declaraciones de voluntad atribuibles a un número plural de personas (por eso conjuntas), probablemente (se precisa, no ciertamente) en ejecución de un pacto sucesorio celebrado entre ellas y, por lo tanto, con el efecto de una odiosa compresión de la libertad y la autonomía testamentarias de cada uno de los testadores 5 (casi como si declarar dos voluntades en el mismo acto fuera siempre señal de una recíproca influencia ilícita). Aun admitiendo, sobre todo entre los autores del pasado, la compatibilidad entre el testamento colectivo y la revocación (cada testador conservaría el derecho de revocar la propia declaración, aunque estuviese acompañada de la declaración de la otra persona), parece que la posibilidad de revocar no supera la mera teoría, ya que de hecho se encuentra inhibida por la advertida necesidad de respetar el acuerdo de los testadores que han querido unir sus respectivas voluntades ${ }^{6}$. En definitiva, la prohibición tendría como objetivo "garantizar que el derecho de revocación pueda ser ejercido sin límites"7.

Entonces, dos o más personas que testan juntas (es decir, que unen en un único acto las respectivas declaraciones de voluntad ${ }^{8}$ ) i) no son libres de cambiar

3 Sobre el particular véase S. Delle Monache, Testamento. Disposizioni generali, en Comm. Schlesinger, Milán, 2005 , p. 235.

4 Así considera G. Tamburrino, “Testamento (dir. priv.)”, en Enc. dir., xliv, Milán, i 992, p. 472. Contra M. Allara, Il testamento, I, Padua, I934, p. I 7 ("en el testamento colectivo las declaraciones coligadas de última voluntad son y permanecen unilaterales”).

5 Escribe F. Filomusi Guelfi, Diritto ereditario, II, Successioni testamentarie, Roma, i 909, p. 4: "La prohibición se encuentra fundada en la necesidad de garantizar la libertad en el acto testamentario, temiéndose que en el testamento simultáneo la libertad del testador sea mermada”. Véase también N. Coviello, Corso completo del diritto delle successioni, II, Nápoles, I9 I 5, p. 348 (quien subraya el hecho de que el testamento colectivo es siempre fruto de un acuerdo que comprime la espontaneidad y la revocabilidad del testamento, es más, de los testamentos contenidos en el mismo acto).

6 Escribe a tal propósito W. D’Avanzo, Delle successioni, II, Florencia, I941, p. 792: “la posibilidad absoluta de la modificación encuentra obstáculo en la fe recíproca, en los vínculos morales y en las consideraciones respecto de los intereses que pudieron haber inducido a dos o más personas a testar conjuntamente".

7 Así, Coviello, Corso completo del diritto delle successioni, cit., p. 349.

8 De manera que "eso que se llama testamento conjuntivo no es un testamento, sino una reunión de testamentos de una pluralidad de personas, usualmente dos, en el mismo acto testamentario", como observa B. Windscheid, Diritto delle pandette, trad. C. Fadda y P. E. Bensa, Turín, I930, III, $\$ 568$, p. 2 I 5 . 
de idea, o ii) se han influenciado recíprocamente y, por lo tanto, no han expresado una voluntad verdaderamente libre y auténticamente personal9.

Pero, ¿en realidad es siempre así?

Fuera de lo que más adelante se referirá sobre la interpretación del artículo 589 , tanto en doctrina como en la praxis jurisprudencial, por ahora se presenta un cuadro general suficientemente claro, que viene acompañado de cierto olvido que parece circundar hoy en día a esta disposición. El debate que a partir de esta se suscitaba con anterioridad era especialmente vivo y rico en referencias históricas, comparatísticas y de derecho internacional privado ${ }^{\mathrm{IO}}$.

La perspectiva histórica sirve para encuadrar de la mejor manera el contexto de formación de la prohibición: ella puede demostrar, de momento, que la prohibición es fruto de una elección histórica y territorialmente contingente, al menos tanto como aquella concerniente a la prohibición de los pactos sucesorios; es tal vez precisamente el nexo entre las dos prohibiciones lo que constituye el núcleo de aquella fortísima protección de la centralidad del testamento que, todavía hoy, parece constituir una característica genética e identificadora del ordenamiento sucesorio italiano.

En el anterior Código Civil italiano, la norma que contenía análoga prohibición, el artículo 761, era idéntica, salvo por alguna pequeña variación de orden formal: sin embargo, la elección de política del derecho había sido sin duda claramente trazada. La vía seguida fue la francesa: ya Pothier, al percatarse de que la Ordonnance de $\mathrm{I} 737^{[\mathrm{r}]}$ había abolido el uso de los testamentos recíprocos, identificó el motivo de esta prohibición en la protección de la libertad del testador, que debía ser puesto a salvo de posibles sugestiones provenientes de las personas junto a las cuales el testamento hubiere sido realizado ${ }^{\mathrm{I2}}$; bajo el

9 ¿Existe realmente una voluntad auténtica y exclusivamente personal o se trata de una utopía, si queremos, de un dogma, que fuera del mundo de las normas podría parecer incluso como el fruto de una excesiva dosis de ingenuidad?

Io Bajo el imperio del viejo código se planteaba el problema de determinar la suerte de los testamentos colectivos (sobre todo entre los cónyuges) surgidos bajo la vigencia de las disposiciones que admitían su validez (Código Civil austriaco de i 8 I I) y ejecutados bajo la vigencia de la prohibición del artículo 76 I del código anterior: ver sobre el punto C. F. GABвA, en Foro it., I886, I, c. 349 (quien apoya la aplicación de la ley vigente al tiempo de la apertura de la sucesión).

I I Artículo Lxxvir: “Abrogeons pareillement l'usage des testaments ou codicilles mutuels ou faits conjointement par mari et femme, ou par d'autres personnes; voulons qu'à l'avenir ils soient regardés comme nuls". Sobre la razón de esta elección se pronuncia Serres, Explication de l'Ordonnance concernant les testaments, Avignone, I 766, p. 334, quien afirma que ella consiste, por una parte, en las dificultades prácticas que estos testamentos generaban en consideración, por ejemplo, de su revocabilidad y, por otra parte, en la constatación de que en la mayor parte de los casos estos eran fruto de adaptación y sugestión (razones que todavía hoy son aducidas para sostener análogas prohibiciones contenidas en las legislaciones modernas).

I 2 R.-J. Pothier, Traité des donations testamentaires, en Oeuvres posthumes de M. Pothier, Orléans, París, I 777, Cap. I, Art. I, p. 296. 
imperio del Code civil (el cual recoge de la Ordonnance el artículo $96^{68^{\left[{ }_{3}\right]}}$ ) surgieron, como ratio de la prohibición, opiniones diferentes de las expuestas por los clásicos, consistentes, por ejemplo, en que la disposición recíproca podía plantear un problema de revocación, puesto que, revocada una de las disposiciones conjuntas, la otra tampoco habría podido sobrevivir, viéndose afectada con una caída automática, en perjuicio de la autonomía de uno de los testadores ${ }^{\mathrm{I}}$.

En conclusión, el testamento conjunto asumía un aire contractual, porque podía razonablemente presumirse, no tanto que fuese en sí un contrato, sino que fuese resultado de un acuerdo dirigido a determinar, conjuntamente, los contenidos del testamento de dos sujetos distintos, o, en teoría, también de más de dos sujetos; y era precisamente esta bilateralidad casi contractual la que justificaba una prohibición a secas, en una óptica de máxima protección de una libertad testamentaria (concebida como exclusivamente) individual y 'unisubjetiva'.

La historia de la prohibición parece entonces confirmar que la unilateralidad es (y siempre ha sido concebida como) una garantía de la libertad; mientras que la pluralidad se entiende como certeza de condicionamiento, en la óptica de un purismo libertario, en razón del cual se tienen como superadas y superables las razones que, por ejemplo en el droit coutumier, justificaban el testamento colectivo $^{15}$-sobre todo el de personas ligadas entre sí por una relación familiar-y que todavía hoy lo tienen por lícito en algunas importantes legislaciones europeas (Alemania: $\$ 2265$ в Gв y Austria: $\$$ I 248 ABG $^{\text {I }}{ }^{6}$ ), en algunas realidades

I 3 "Un testament ne pourra être fait dans le même acte par deux ou plusieurs personnes soit au profit d'un tiers, soit à titre de disposition réciproque ou mutuelle".

I4 Sobre el punto es suficiente consultar Duranton, Corso di diritto civile secondo il codice francese, Nápoles, I 854 , libro III, p. 7, n. $^{\circ}$ 9. Otra parte de la doctrina sostiene que el testamento conjunto, al impedir la revocatoria, si no es conjunta, debe prohibirse precisamente porque atenta contra la absoluta revocabilidad del testamento: en este sentido, V. Marcadé, Spiegazione teorico-pratica del Codice Napoleone, Nápoles, I875, vI, p. 4. Sobre el punto es clara la identificación de los motivos que indujeron al legislador de r 804 a confirmar la prohibición: "permitir la revocatoria es violar la fe de la reciprocidad; la declaratoria de irrevocabilidad es cambiar la naturaleza del testamento, que en ese caso no es realmente un acto de la última voluntad": P. A. Fenet, Recueil complet des travaux préparatoires du Code civil, xII, Osnabrück, I968, reimpr., p. $55^{2}$.

I 5 No es claro cuál fuese el tratamiento jurídico del testamento colectivo en el derecho romano, que habría sido reconocido por una constitución de Valentiniano iI en el año 446 (siempre con referencia al testamento entre cónyuges): sobre el punto basta consultar Windscheid, Diritto delle pandette, cit., $\$ 568$, p. 2 I 6 , nota 2 y, para una lectura integral de la Novela de Valentiniano iII, cfr. A. Dernburg, Pandette, iII, Diritto di famiglia e diritto dell'eredità, trad. Cicala, Turín, I $906, \$ 97$, p. $35^{2}$, nota 5 .

I6 Ambos ordenamientos admiten el testamento común entre los cónyuges; al $\$$ I 248 ABG se adiciona que también ese testamento puede ser revocado "pero de la revocatoria de una de las partes no puede deducirse también la revocatoria de la otra". Es evidente la influencia austroalemana sobre el nuevo Código Civil de Hungría, el cual entró en vigor en marzo de 2014 (el artículo 7:23 admite el testamento conjunto pero solo entre cónyuges y con el respeto de algunas condiciones de forma). 
del derecho foral español ${ }^{17} \mathrm{y}$, desplazando la atención fuera del área del civil law, también en el área anglosajona, que conoce y admite los mutual wills ${ }^{18}$. En todos estos casos, generalmente, el testamento colectivo de los cónyuges es válido, y su eficacia está casi siempre reforzada por previsiones (tanto legislativas como de matriz jurisprudencial) que inhiben la revocación al testador sobreviviente.

Si se mira al ordenamiento jurídico italiano, tal vez la ratio también histórica de la prohibición aparezca clara y, en cierto modo, admisible. Lo que no es todavía claro del todo es el verdadero ámbito de aplicación de la prohibición, al no poderse trazar una nítida demarcación entre las áreas de segura aplicación y aquellas, quizá contiguas, que en cambio pueden ser excluidas. Así pues, ha llegado el momento de superar cierta rigidez "unipersonalista" fruto de concepciones utópicas y alejadas de la realidad, apareciendo evidente que la formación de la voluntad testamentaria, sobre todo en ciertos contextos familiares, está naturaliter sujeta a condicionamientos e influencias que, lejos de representar limitaciones indebidas a la libertad del particular, constituyen, más que todo, el ambiente ideal en el cual viene a formarse la voluntad dispositiva, no solo orientada a perseguir un fin regulatorio patrimonial, sino motivada también por el normal impulso ejercitado por relaciones, sentimientos, vínculos .

No se trata de dar relevancia a "acuerdos" externos al testamento o que tienen como fin sustituirlo; se trata, ante todo, de recuperar jurídicamente aquel conjunto de circunstancias, por así llamarlas "existenciales", que fisiológicamente están presentes en la formación del negocio testamentario, y que no parecen representar atentados intolerables a la libertad individual; circunstancias que pueden, y tal vez deben, encontrar desahogo en el testamento y no en negocios diferentes.

I $7 \mathrm{El}$ artículo 669 C.C. español reproduce una prohibición análoga a la de los códigos francés e italiano ("No podrán testar dos o más personas mancomunadamente, o en un mismo testamento, ya lo hagan en provecho recíproco, ya en beneficio de un tercero"); no obstante, en el derecho civil foral son admitidos los testamentos conjuntos, los cuales constituyen una segunda tipología de testamentos al lado de los normalmente unilaterales: así, por ejemplo, la Compilación de Aragón (en la versión derogada por la Ley i/ı 999), en los artículos 94 a 97; del mismo modo cfr. la Compilación de Navarra (leyes i 99 a 205), la cual admite el llamado testamento de hermandad. En Suramérica la prohibición de testamento colectivo aparece también en todos los códigos civiles, como se observa, a título de ejemplo, en el artículo 2465 del nuevo Código Civil argentino, en el artículo i 863 C.C. brasileño (que tal vez representa la forma más amplia de prohibición, pues comprende expresamente también los testamentos simultáneos y los equivalentes), en el artículo roo3 C.C. chileno, en el artículo ro59 C.C. colombiano y en el artículo 8 I 4 C.C. peruano.

I 8 Que admite (siempre entre cónyuges) los llamados joint o mutual wills, sobre los cuales se remite a C. H. Sherrin, R. F. D. Barlow y R. A. Wallington, Law relating to Wills, I, Londres, I 980, pp. I 7 ss. y a P. Birks (ed.), English Private Law, Oxford, 2000, 7. I I6. En Estados Unidos merece mención el Código Civil de Luisiana que reproduce la prohibición de origen francés (art. I 57 I). 


\section{Viejas problemáticas que recobran actualidad: ¿prohibición de naturaleza formal o sustancial?}

Regresando a nuestros días, el artículo 589 del codice civile plantea todavía problemas (i) de investigación sobre su fundamento y, consecuentemente, (ii) de determinación de su alcance aplicativo. Sobre el primer aspecto, la cuestión está aún abierta y se puede sintetizar en el tradicional interrogante de si la prohibición se apoya en razones de forma o de sustancia ${ }^{\mathrm{I} 9}$; es decir, si la prohibición responde a razones de forma -o mejor, se entiende que es una expresión del principio por el cual un documento testamentario puede contener solo una declaración de voluntad y no más que una- o si responde a razones de sustancia -o mejor, se entiende que es una expresión de un principio general en virtud del cual, independientemente del aspecto formal o documental, si hay una recíproca influencia de las voluntades, el testamento es nulo (pero si no la hay, tendría que preguntarse: ¿es válido?).

Si bien se observa, en la doctrina, incluso solo en la más reciente ${ }^{20}$, parece reinar la incertidumbre, y únicamente aceptando una alta probabilidad de error podría identificarse una opinión dominante. Si se tratase de una nulidad sustancial, el artículo 589 del codice civile sería solamente una ulterior, y tal vez inútil, confirmación de la prohibición de los pactos sucesorios ${ }^{21}$ y vendría a debilitarse fuertemente -al menos en su faceta de prohibición- bajo un perfil (como mínimo) doble: i) al requerir al intérprete, en cada caso, comprobar si la duplicidad de las suscripciones es o no es atribuible a un acuerdo prohibido del que descienda, incluso, una efectiva limitación de las recíprocas voluntades testamentarias; o ii) al permitir soslayar la nulidad si, venciendo una especie de presunción relativa, establecida por la misma disposición, se lograra demostrar que la pluralidad de las suscripciones no conlleva la efectiva lesión de la libertad de los testadores ${ }^{22}$. De modo que, como sucede en Francia, la nulidad del testamento colectivo se verifique a través de una comprobación de tipo objetivo-formal (unicidad del documento en el cual se encuentran contenidas las disposiciones

I9 Pregunta que también tiene sentido plantearse debido a sus consecuencias de derecho internacional privado, porque si se trata de una invalidez por razones de forma, la ley aplicable es aquella del Estado en el cual el testador dispuso (art. 48 de la ley de derecho internacional privado); si es invalidez sustancial, la ley aplicable es la del sujeto de cuya herencia se trata (art. 46 de la ley de derecho internacional privado).

20 Cfr. S. Landini, Le invalidità del negozio testamentario, Nápoles, 20 I 2, pp. I I - 2 (quien atribuye la prohibición al área formal, pero reconoce también las razones de carácter sustancial que justifican la previsión).

2 I Así considera L. Bigliazzi Geri, Successioni testamentarie, en Comm. Scialoja-Branca, BoloniaRoma, I993, p. I47.

22 Siempre que la presunción establecida por el artículo 589 del codice civile no sea considerada como absoluta, sino como relativa: en este sentido G. Azzariti, Le successioni e le donazioni, Nápoles, I990, pp. 4I4-4I 5 . 
testamentarias que se atribuyen a un número plural de personas) y otra de tipo subjetivo-psicológico (que el acto exprese una voluntad efectivamente conjunta de los dos testadores) ${ }^{2} 3$.

El sistema no puede ser tan complicado y el artículo 589 del codice civile merece una interpretación, por una parte, más simple, y por otra, respetuosa en mayor medida de su sentido histórico: la prohibición debe ser adscrita al área de la forma ${ }^{24}$, en el sentido de que si en el documento testamentario (el "mismo acto”, según se lee en el artículo 589) aparecen dos o más suscripciones (que refieran a dos o más personas una única declaración de voluntad o varias declaraciones de voluntades recíprocas efectuadas en el mismo acto), el testamento debe sin duda considerarse afectado de nulidad, y, por lo tanto, prohibido por el artículo 589 del codice civile; que esto derive o no de una influencia recíproca es sustancialmente irrelevante, salvo que se quiera reconocer en esta circunstancia una de las razones, tal vez también la más significativa, que se encuentra en la base de la previsión legislativa de la prohibición.

Entonces, si se trata del aspecto formal consistente en la reunión en un único documento de varias voluntades recíprocas o conectadas, la prohibición a que se refiere el artículo 589 del codice civile puede ser circunscrita en su área de aplicación: es evidente que éste no podría ser aplicado ni a los testamentos simultáneos ni a los mirror wills.

\section{Nuevas lecturas jurisprudenciales: ¿hacia la validez de los mirror wills?}

La jurisprudencia más reciente parece haberse convencido de la bondad de esta aproximación, dando el paso, por así decirlo, hacia una reconfiguración (o, tal vez, hacia una nueva distribución) de la prohibición, en relación con todas aquellas situaciones (en doctrina denominadas o clasificadas de manera no siempre coincidente) que evocan o tocan el testamento conjunto, pero que no pueden comprenderse en el área de aplicación de la prohibición: como lo son el denominado testamento simultáneo (declaraciones contenidas en el mismo documento, pero suscritas de manera separada y autónoma) y los mirror wills (testamentos de idéntico contenido redactados en documentos separados y del todo autónomos el uno respecto del otro).

23 En este sentido cfr. P. Malaurie y L. Aynès, Cours de droit civil, Les successions, París, ig89, p. 236.

24 El mejor representante de esta tesis es Allara, Il testamento, cit., p. 2 I ss.; se pueden adscribir también a esta opinión A. Cicu, Il testamento, Milán, I 942, p. 28 ss.; Bigliazzi Geri, Successioni testamentarie, cit., p. I47; C. M. Bianca, La famiglia. Le successioni, Padua, I98 I, p. 494. Contra véase, en general, S. Delle Monache, Testamento. Disposizioni generali, en Comm. Schlesinger, Milán, 2005 , pp. 247-248. 
En una reciente decisión, la Casación italiana ${ }^{25}$ hizo claridad sobre estos importantes aspectos, y también se manifestó sobre la vexata quaestio de la naturaleza de la prohibición del artículo $5^{89}$ del codice civile. Según los jueces de conocimiento, la prohibición de los testamentos conjuntos o recíprocos da lugar a una nulidad de carácter formal, que sin embargo se activa solo en presencia de circunstancias de hecho extremadamente rigurosas: en efecto, afirma la Casación italiana:

... el legislador quiso establecer una presunción absoluta de falta de libre y espontánea expresión de la voluntad de los testadores por haber respondido en el "mismo acto" en las dos formas del testamento conjunto simple o del testamento conjunto recíproco, sin que sea posible probar que la conjunción de las disposiciones testamentarias sea un hecho meramente extrínseco y que no haya comprometido la libertad de la voluntad de los declarantes; por lo tanto, la norma en examen sanciona con nulidad las hipótesis de un único testamento que contiene dos o más suscripciones en violación de los requisitos formales del testamento hológrafo, donde es evidente la exigencia de una actividad de redacción y suscripción del acto por parte de un único sujeto.

Continúa la Corte advirtiendo que la sanción de nulidad no puede proceder en presencia de escrituras testamentarias separadas, puesto que, por un lado, el legislador "ha considerado la previsión expresa de tan grave sanción solamente en los casos arriba enunciados, sin que evidentemente recaiga, en el caso de escrituras testamentarias separadas, la presunción absoluta de falta de una libre exteriorización de la voluntad de los testadores, propia del testamento conjunto y que corresponde a una manifestación de la voluntad de los testadores en un documento unitario"; y, por el otro, concluyen los jueces de la Corte, "lo asumido en orden a la interpretación rigurosamente restrictiva de la prohibición prescrita por la norma en examen, se compadece con el hecho de que es comúnmente sostenido en relación con que no todos los testamentos contenidos en el 'mismo acto' están sujetos a la sanción de nulidad, no dudándose de la legitimidad de los testamentos denominados simultáneos, es decir, de aquellas declaraciones de última voluntad contenidas en un mismo documento, pero autónomas entre sí".

Así pues, la prohibición a la que hace referencia el artículo $5^{89}$ del codice civile debe ser interpretada, como todas las prohibiciones, en sentido rigurosamente restrictivo: si, como escribe la Casación, pueden ser válidos también los testamentos redactados en una misma hoja (cuando se pueda constatar su perfecta autonomía $\left.{ }^{26}\right)$, ciertamente deben considerarse como excluidos de la

25 Cassazione civile del 5 de abril de 20 i 2, n. $^{\circ} 5508$ (sobre la cual cfr. A. M. Benedetti y S. PagLianTINI, Profili sull'invalidità e la caducità delle disposizioni testamentarie, Nápoles, $20 \mathrm{I} 3$, xv ss.).

26 Cfr. en tal sentido también la Cassazione civile del i 8 de julio de I959, n. ${ }^{\circ}{ }_{2} 64$, en Vita not., 
aplicación de la prohibición de que habla el artículo 589 del codice civile, como exactamente ha sido establecido por la Corte en la decisión arriba señalada, aquellos testamentos de dos testadores, redactados en escrituras diferentes (aun el mismo día), cuando pese a tener el mismo contenido, cada uno de ellos, de hecho, conserva intacta la amplia y espontánea libertad de revocación, cuya protección constituye la ratio de la prohibición a la que se refiere el artículo 589 y que solo se vería minada en el caso de un único testamento redactado de manera conjunta en un mismo documento ${ }^{27}$.

Si falta el presupuesto formal (unicidad del documento) sobre el cual construye el artículo 589 del codice civile su propia aplicación, es posible, de forma abstracta, considerar, bajo el aspecto sustancial, si dos testamentos redactados de manera separada violan otros principios que gobiernan la materia testamentaria: pero en todo caso es necesario suministrar la prueba rigurosa de un pacto sucesorio ${ }^{28}$ subyacente a los dos testamentos, de un acuerdo específicamente celebrado entre los dos testadores relativo a los contenidos y/o a la irrevocabilidad de los dos actos, con el fin de obtener en sede judicial una declaración de nulidad de los mismos, siendo evidente que la carga de suministrar la prueba de los hechos sobre los cuales se pretende construir la posible nulidad de los dos actos recaería en quien quisiese controvertir judicialmente la validez de los testamentos ${ }^{29}$.

Por otra parte, en respeto del favor testamenti, no corresponde a quien defiende la validez de los testamentos simultáneos o de los mirror wills desmentir presunciones de invalidez que no existen, principalmente porque se trata de

I959, p. 624; cfr. sobre el punto, en línea con la orientación expresada actualmente por la Cassazione, M. Di Marzio y S. Matteini Chiari, Le successioni testamentarie, Milán, 20i3, pp. $43-45$.

27 Cfr. sobre el particular G. Giampiccolo, Il contenuto atipico del testamento, Milán, i954, pp. 342-343.

28 Como ha decidido la Cassazione civile del 27 de abril de $1982,{ }^{\circ}{ }^{\circ}{ }_{2} 623$ : "se tiene pacto sucesorio, prohibido, de acuerdo con lo dispuesto por el artículo $45^{8}$ C.C., cuando las disposiciones testamentarias redactadas por una pluralidad de personas, aun estando contenidas en escrituras formalmente distintas, se integran recíprocamente, dando lugar a un acuerdo con el cual cada uno de los testadores dispone de su sucesión de cierto modo, en determinante correlación con la concordada disposición de los bienes hecha por otro (en el caso: se verificó un pacto sucesorio prohibido, en el cual cada uno de los cónyuges había dejado sus propios bienes a uno de los dos hijos, pues el otro cónyuge había dispuesto de sus haberes en favor del otro hijo)".

29 Significativa, en el sentido indicado en el texto, la sentencia del Tribunal de Terni del I 3 de septiembre de 2007: "la falta de pruebas específicas idóneas para demostrar el perfeccionamiento de un pacto sucesorio subyacente, la identidad, el contexto y la reciprocidad de los testamentos, no permite concluir que los mismos hayan sido redactados en ejecución de un preciso vinculum iuris". Contra sentencia del Tribunal de Milán del 2 de noviembre de I998, en Giur. merito, 2000 , p. 596 (según la cual dos testamentos de idéntico contenido, aunque redactados en actos formalmente separados, han de ser considerados como "sustancialmente recogidos en un mismo acto"). 
situaciones ajenas a la prohibición de que trata el artículo $5^{89}$ del codice civile ${ }^{30}$ y que por tanto, si acaso, están asistidas por una presunción de validez.

Para sostener la nulidad de estos testamentos no bastaría, por lo demás, un mero compromiso moral de los dos testadores de testar en modo idéntico, porque eso no podría ser suficiente por sí solo para configurar un pacto sucesorio (ni, mucho menos, para volver "recíprocos" dos testamentos de idéntico contenido pero redactados en documentos separados) ${ }^{3 \mathrm{I}}$.

A esto se debe adicionar que la misma prohibición, en cuanto es de naturaleza formal, no debe considerarse como violada sic et simpliciter en razón de la presencia en la escritura testamentaria de suscripciones atribuibles a personas diferentes del testador, porque estas pueden ser irrelevantes o, de todas maneras, no son tales como para llevar a considerar que el testamento, en su contenido compromisorio, se pueda referir a la voluntad de varios sujetos ${ }^{32}$. La unicidad documental -núcleo de la prohibición-debe expresarse o en una única declaración de voluntad atribuible a dos sujetos, o en varias declaraciones recíprocas; fuera de estos supuestos, la nulidad que prevé la prohibición no puede presentarse 33 .

Por lo tanto, se infiere que tanto los testamentos denominados simultáneos como los mirror wills (es decir, testamentos formalmente separados pero que tienen un idéntico contenido, incluso la recíproca designación de los testadores como herederos ${ }^{34}$ ) no pueden por sí mismos, y salvo la aplicación de la

30 Contra se expresa Delle Monache, Testamento. Disposizioni generali, cit., p. 246, según el cual los testadores simultáneos tendrían que ser comprendidos en la prohibición de los testamentos conjuntos (el autor, de otra parte, se adhiere a la idea consistente en que la prohibición no puede ascender al rol de ulterior prescripción sobre la forma de los testamentos).

3 I En tal sentido, Cassazione civile del 8 de octubre de 2008, n. $^{\circ} 248$ I 3 , en Riv. notariato, 2009 , p. 234 y p. 678.

32 Por ejemplo, en la Cassazione civile del 5 de agosto de 2002, n. ${ }^{\circ}$ I I 733, la Corte Suprema excluyó la nulidad de un testamento que contenía la disposición última de voluntad integralmente escrita por el de cuius y que, inmediatamente abajo, contenía suscripciones hechas por mano ajena; o, aun, en Cassazione civile del 3 de noviembre de 2008 , que excluyó la nulidad de un testamento que contenía incisos apócrifos, o en Cassazione civile del 30 de octubre de 2008, n. $^{\circ} 26258$, que consideró como subsistente el requisito de la autografía también en el caso en que en el mismo documento físico se encuentren escritos atribuibles a la mano de un tercero. Es además pacífico en la jurisprudencia que las declaraciones de ciencia (es decir, concernientes a la comprobación de los hechos) no hagan parte del negocio testamentario precisamente porque no es posible calificarlas como declaraciones de voluntad (en tal sentido la Cassazione civile del 26 de abril de I 984, n. $^{\circ} 2632$, que excluyó que pueda configurarse un negocio testamentario en el caso en que el testador, en la escritura testamentaria, haya adoptado una declaración de ciencia dirigida a reconocer la propiedad de determinados bienes en cabeza de un determinado sujeto).

33 Conclusión que no choca ni siquiera con la interpretación de la disposición-modelo del artículo 968 del Code civil, tal como lo confirma la afirmación de C. S. Zachariae, Corso di diritto civile francese, trad. ital., Nápoles, I85 I, p. 29: "Pero nada impide que varias personas hagan, la una en favor de la otra, mediante actos separados, aunque en el mismo momento, disposiciones recíprocas de última voluntad".

34 También llamados testamentos equivalentes: M. G. Falzone Calvisi, Diritto successorio. Temi e problemi, I, Milán, 20 I 2, p. I I 5 
prohibición de los pactos sucesorios, ser sancionados con la nulidad expresada en el artículo 589 del codice civile; si esto es exacto, en el ordenamiento italiano el alcance de la prohibición parece reconfigurado, y aparecen nuevos resquicios ante situaciones en las cuales la recíproca influencia no sería una patología que debe ser curada, sino una dimensión fisiológica de una comunidad existencial que puede encontrar eco en el testamento.

En estos casos, los testadores no celebran necesariamente un pacto sucesorio (en el supuesto de que lo hicieran, incurrirían en la prohibición del artículo 458 del codice civile), sino que expresan, en dos documentos diferentes, dos voluntades libres (en tanto y a condición de que 35 sean revocables, dada la diversidad de los actos en los cuales están contenidas), pero correlacionadas, conectadas, unidas por un idem sentire que realiza plenamente la libertad de disposición de los dos testadores ${ }^{36}$. Ciertamente, no se trata de legitimar influencias indebidas sobre la voluntad del testador que, entre otras cosas, son objeto de prohibiciones y sanciones previstas por otras disposiciones en materia de vicios del testamento ${ }^{37}$; se trata, si acaso, de abrir la puerta también en el ordenamiento italiano a figuras -como la del testamento interconyugal ${ }^{3}$ - que puedan encontrar carta de ciudadanía gracias a las nuevas lecturas del artículo 589, menos centradas en la "prohibición" y más coherentes con la exigencia, propia de una sociedad madura, de permitir a la autonomía privada sucesoria y testamentaria un desarrollo pleno y libre de ataduras que compriman al punto de ser casi asfixiantes ${ }^{39}$.

35 De hecho, como es evidente, si los dos testamentos, en cuanto redactados separadamente, estuvieren jurídicamente conectados, por ejemplo a través de una condición de reciprocidad, tendría aplicación la nulidad que dispone el artículo 635 del codice civile; pero debe tratarse, en buena medida, de una "interdependencia sustancial entre las disposiciones" (cfr. E. Bergamo, "Art. 589", en Commentario del Codice civile, dir. da E. Gabrielli, Delle successioni, a cura di V. Cuffaro y F. Delfini, Turín, 20io, p. i86).

36 Siempre que naturalmente no haya incurrido en dolo/captación: sobre el particular cfr. S. $\mathrm{P}_{\mathrm{A}}-$ gliantini, I vizi della volontà testamentaria, en Benedetti y Pagliantini, Profili sull'invalidità e la caducità delle disposizioni testamentarie, cit., pp. 53 ss.; sobre la necesidad de proteger la libertad testamentaria de nuevas formas de influencia indebida, y sobre las modalidades para realizar este objetivo con las reglas actualmente vigentes, cfr. S. PATTI, "Il testamento olografo nell'era digitale", en Riv. dir. civ., 2014, I, p. 992 ss.

37 En efecto, esta parece ser la ratio de las prohibiciones de testar en favor del tutor y del protutor (art. 596 codice civile), en favor del notario, de los testigos y de los intérpretes (art. 597 codice civile), en favor de los curadores (art. 4I I codice civile).

38 Como L. Barassi, Le successioni per causa di morte, Milán, I94I, p. 209, definía con gran eficacia: "expresión casi simbólica de unión espiritual que se irradia en los patrimonios incluso luego de la muerte".

39 Una lectura que, en el fondo, se hacía también bajo el impero del código italiano anterior, en el cual la prohibición de los testamentos conjuntos tenía un tenor análogo al que hoy está vigente: ver Cassazione civile del 30 de julio de 1937, n. ${ }^{\circ} 2942$, en Foro it., I938, c. 400 (la reciprocidad de las disposiciones no determina un testamento colectivo, en tanto estas se encuentren contenidas en dos actos perfectamente distintos). En tiempos más recientes, el Reglamento uE (Unión 


\section{Bibliografía}

Allara, Il testamento, I, Padua, I934.

Azzariti, Le successioni e le donazioni, Nápoles, I 990.

Barassi, Le successioni per causa di morte, Milán, I94 I.

Benedetti y Pagliantini, Profili sull'invalidità e la caducità delle disposizioni testamentarie, Nápoles, 2013.

Bergamo, Art. 589, en Commentario del Codice civile, dir. E. Gabrielli, Delle successioni, a cura di V. Cuffaro e F. Delfini, Turín, 20 io.

Bianca, La famiglia. Le successioni, Padua, i 98 I.

Bigliazzi Geri, "Successioni testamentarie”, en Comm. Scialoja-Branca, BoloniaRoma, I993.

Birks (ed.), English Private Law, Oxford, 2000.

Bonilini, "Il negozio testamentario", en Trattato di diritto delle successioni e delle donazioni, dir. G. Bonilini, II, La successione testamentaria, Milán, 2009.

Cicu, Il testamento, Milán, i 942 .

Coviello, Corso completo del diritto delle successioni, iI, Nápoles, i 9 I 5.

D’Avanzo, Delle successioni, II, Florencia, I94I.

De Nova, Il contratto. Dal contratto atipico al contratto alieno, Padua, 20 I I .

Delle Monache, “Testamento. Disposizioni generali”, en Comm. Schlesinger, Milán, 2005.

Dernburg, Pandette, in, Diritto di famiglia e diritto dell'eredità, trad. Cicala, Turín, I906.

Di Marzio y Matteini Chiari, Le successioni testamentarie, Milán, 20 i 3.

Duranton, Corso di diritto civile secondo il codice francese, Nápoles, i 854, libro III.

Falzone Calvisi, Diritto successorio. Temi e problemi, I, Milán, 20 I 2 ,

Fenet, Recueil complet des travaux préparatoires du Code civil, xII, Osnabrück, I968, rist.

Filomusi Guelfi, Diritto ereditario, II, Successioni testamentarie, Roma, I 909.

Gaвва, in Foro it., I886, I, c. 349.

Giampiccolo, Il contenuto atipico del testamento, Milán, i 954.

LANDIni, Le invalidità del negozio testamentario, Nápoles, 20 I 2.

Malaurie y Aynès, Cours de droit civil, Les successions, París, i 989.

Europea) n. ${ }^{\circ} 650 / 2012$ se refiere a las "disposiciones por causa de muerte", sin distinguir los testamentos unipersonales y los conjuntos (art. 3 , lits. b-c). 
Marcadé, Spiegazione teorico-pratica del Codice Napoleone, Napolés, I875, vi.

Pagliantini, Causa e motivi del regolamento testamentario, Nápoles, 2000.

Palazzo, Le successioni, **, en Tratt. dir. priv., Milán, 2000.

РАтті, "Il testamento olografo nell'era digitale", en Riv. dir. civ., 20 I4, I.

Pothier, Traité des donations testamentaires, en Oeuvres posthumes de M. Pothier,

Orléans, París, I 777.

Serres, Explication de l'Ordonnance concernant les testaments, Avignone, I 766.

Sherrin, Barlow y Wallington, Law relating to wills, I, Londres, I980.

Tamburrino, “Testamento (dir. priv.)”, en Enc. dir., xliv, Milán, i 992.

Windscheid, Diritto delle pandette, trad. ital. C. Fadda y P. E. Bensa, Turín, I930, III.

Zachariae, Corso di diritto civile francese, trad. ital., Nápoles, I 85 I. 